\section{Japan's demography poses questions for old and young allike}

[TOКYO] Japan faces even more rapid ageing and decline in numbers of its population than previously estimated, according to a study released last week by the Ministry of Health and Welfare's Institute of Population and Social Security Research. The gloomy projections do not bode well for the country, which is already confronted with an unfavourable economic future.

The institute predicts that Japan's population will peak at just under 128 million in 2007, four years earlier than estimated in a survey in 1992, and will decline steadily thereafter to 100 million by 2050 . This latest estimate is based on demographic projections from an analysis of the 1995 population census, the birth rate and life expectancy.

The population of people over 65 will rise rapidly to 32 million by 2015 , constituting a quarter of the population (compared with 15 per cent at present), while the working-age population, aged between 15 and 64 , that has to support them, will fall from 87 to 76 million. The working population will continue a steady decline to only 55 million - barely half the population - in 2050.

In 1994, Japan was eleventh in the league of developed nations with large elderly populations; Sweden topped the list, with 17.5 per cent of the population over 65 . But by 2015 Japan will have the world's largest proportion of elderly people.

The pessimistic projections are driven by a declining birth rate, which dropped to a record low of 1.42 per woman in 1995, and high life expectancy, which stood at 83.0 years for women and 76.6 years for men in 1994. The institute projects that life expectancy in Japan will rise to 86.5 for women and 79.4 for men by 2050 because of improved health care, while the birth rate will continue to decline to 1.38 in 2000 and then rise gradually to 1.60 by 2022 . The 1992 survey had predicted a recovery in the birth rate from 1995 onwards, but that has proved wrong.

The projections of a more rapidly ageing society combined with a more rapid decline in the working-age population will put an enormous strain on the national healthinsurance system, which is already destined to plummet into the red unless there are major reforms requiring patients and working people to pay more.

Analysts say that the latest projections are expected to drive the pharmaceutical industry to invest even more heavily than it is already doing in the development of drugs to treat the diseases of old age, such as Alzheimer's disease.

DavidSwinbanks

\title{
Canada and France fall out over the risks of asbestos
}

[PARIS AND MONTREAL] Sharp differences are emerging between the federal government of Canada and Canadian and other health experts over the government's decision to ask France to rethink a recent ban on asbestos. Canada is the world's largest exporter of the material.

The government argues that a scientific report by an international panel set up under the auspices of the Royal Society of Canada (RSC) undermines the findings of a report by an expert panel of INSERM, France's national biomedical research agency, that was released on the eve of the ban last July.

Jean Chrétien, Canada's prime minister, said in Paris during a state visit to France last week that the Canadian

report would "convince" France to reconsider its ban and show UNAVAILABLE that "there were ways to FOR use asbestos safely".

A statement from the Canadian government said that INSERM had "overestimated the real threat of asbestos to Chrétien: wants ban the French population". to be reviewed.

But some members of the RSC panel that produced the report have distanced themselves from the political use being made of it.

Robert Haynes, president of the RSC, says that the setting-up of expert panels "at arm's length" from government is a vital role of the society. But he says that the panel's conclusions say nothing about the validity of the French ban. The RSC itself "is absolutely not putting any political interpretation" on the study, he says.

Haynes is not surprised by the political interpretation of the study. "It is inevitable in such controversial issues that politicians will read whatever they want into it," he says. "Even the devil can quote scripture to his own ends."

Enzo Merler, an Italian scientist on the panel who works at the International Centre for Cancer Research in Lyon, France, says it is "wrong" to use the panel's findings to argue for a lifting of the ban. He argues that Canada commissioned the report to support " $\mathrm{a}$ position against France", adding that he personally feels the INSERM report was of "exceptional quality, exactitude and comprehensiveness".

Merler says: "Risk estimates are just one input into social, economic and political judgements". He argues that decisions on whether to ban asbestos depend on many other factors such as economic feasibility, and the availability of safe substitutes.
France was right to ban asbestos, argues Merler. He says that it is difficult to apply safety measures in areas such as building maintenance, where workers are exposed to low levels of asbestos."

The RSC panel also points out in its report that it was asked for a critical analysis of the INSERM report, and it is therefore not surprising that much of its comments are negative. F. Kenneth Hare, chairman of the RSC panel and a professor emeritus at the University of Toronto, says for example, that "although the French unquestionably have a problem, it isn't quite as grave as the [INSERM] report says".

Hare emphasizes that the panel agreed with much of the INSERM report, including its conclusion that all forms of asbestos are carcinogenic. Hare says that the Quebec government, in particular, "has got a problem on its hands". Asbestos represents 7 per cent of Quebec's exports, and in 1994 the province accounted for 524,000 of the 531,000 tons - worth some C $\$ 233$ million (US\$179 million) — produced in Canada as a whole. Although Canada exports just 6 per cent of this to France, it is concerned that other countries may follow the French move. Chrétien has said that he intends to fight the ban at the World Trade Organization.

The RSC study has itself come under criticism. The fact that it was produced within a few weeks is criticized by three of the four external academics to whom it was sent for peer review. One pointed out that corresponding studies elsewhere often take years. "Whoever decided on these constraints [of time] cannot have had any idea of the complexity of the questions that had to be addressed," says another, adding that the panel had done a "good job" given the circumstances.

Officials at INSERM are also upset that, although the RSC review has been released to the press, the agency has not yet been formally sent a copy. Marcel Goldberg, one of the rapporteurs of the INSERM report, says this makes it impossible to comment on the panel's criticisms. "It's extraordinarily improper," he says. Haynes replies that the RSC was under contract to deliver its report to Canada Health, but agrees that it "would have been desirable" for the latter to have sent INSERM a copy.

The allegedly surreptitious manner by which the RSC obtained the INSERM report has also created ill-feeling. "I don't know how they got it," says Goldberg, who says no formal request was ever made. Haynes says that he is unaware of how the report was obtained.

DeclanButler \& David Spurgeon 